\title{
OUTRO MAR, OUTRO EU: UMA LEITURA SOBRE A NATUREZA METAFÓRICA DE PAISAGEM COM MULHER E MAR AO FUNDO
}

\author{
Mariana Marques de Oliveira* \\ Universidade Federal do Rio de Janeiro
}

\begin{abstract}
Resumo: A obra Paisagem com mulher e mar ao fundo, de Teolinda Gersão, foi publicada oito anos depois da Revolução dos Cravos e trouxe como pano de fundo as décadas de regime ditatorial em Portugal. Dado esse contexto, momento em que foi necessário ressignificar e revisar esse passado tão recente na tentativa de compreendê-lo, pretende-se analisar de que modo a linguagem é um espaço de onde emerge um outro olhar sobre o passado de crueldade e sofrimento. Neste trabalho, veremos como a metáfora e a metonímia podem promover um espaço de ressignificações na linguagem. Tal como a paisagem, o olhar sobre mar - símbolo da cultura, memória e história portuguesas -, ao lado de seus elementos circundantes, será revisitado e revisado, agora sobre tal contexto. Os corpos "despedaçados" das personagens serão a metáfora de um corpo social português destruído e devastado em sua identidade cultural. Os estudos de Roland Barthes, Renato Cordeiro Gomes, Ângela Beatriz Faria, Denilson Lopes, Eduardo Lourenço, entre outros, serão as fontes de fundamentação teóricocrítica do trabalho.
\end{abstract}

Palavras-chave: Paisagem com mulher e mar ao fundo. Teolinda Gersão. Memória. Salazarismo. Revolução dos Cravos.

Lisboa tem barcas agora lavradas de armas

Lisboa tem barcas novas agora lavradas de homens

Barcas novas levam guerra as armas não lavram terra

São de guerra as barcas novas no mar mandadas com homens

Barcas novas são mandadas sobre o mar

Esta obra está licenciada sob uma Licença Creative Commons.

\footnotetext{
* Licenciada em Letras pela Universidade do Estado do Amazonas (UEA). Mestranda do Programa de PósGraduação em Letras Vernáculas na Faculdade de Letras da Universidade Federal do Rio de Janeiro (UFRJ) e bolsista do Programa de Apoio à Formação de Recursos Humanos Pós-Graduados do Estado do Amazonas pela Fundação de Apoio e Amparo à Pesquisa no Amazonas (FAPEAM).
} 
Não lavram terra com armas os homens

Nelas mandaram meter os homens com a sua guerra

Ao mar mandaram as barcas novas lavradas de armas

Em Lisboa sobre o mar armas novas são mandadas (Fiama Hasse Pais Brandão, Barcas Novas)

Esta madrugada que eu esperava $O$ dia inicial inteiro e limpo Onde emergimos da noite e do silêncio E livres habitamos a substância do tempo (Sophia de Mello Breyner Andresen, 25 de abril)

As epígrafes de uma obra ou de um texto geralmente têm como intuito indicar uma síntese, um mote, uma ideia-chave do que vem a seguir na leitura. Tal inscrição inicial dialoga muitas vezes com outros textos, uma vez que ela se configura como um lugar privilegiado para citações de outros autores. Os textos se comunicam, então, por meio de um destaque, que provém de uma escolha, dado pelo escritor ao trazer transcrita uma ou várias citações como abertura da sua obra. Por fugir estrategicamente à "regra", a epígrafe de Paisagem com mulher e mar ao fundo (1982), de Teolinda Gersão, ${ }^{1}$ merece destaque. Ei-la:

\footnotetext{
Na pág. 78, a definição de arquitectura e a frase 'as cidades como fruta podre' são de Le Corbusier, a pág. 131 inclui um passo das Memórias de Raul Brandão.

O resto do texto também não é meu. De diversos modos foi dito, gritado, sonhado, vivido por muitas pessoas, e por isso o devolvo, apenas um pouco mais organizado debaixo desta capa de papel, a quem o reconheça como coisa sua. T.G. (PMMF, p. 5)
}

Assim como toda epígrafe, esta traz tanto a chave de leitura para a obra, quanto dialoga com outros textos. Contudo, singulariza-se por trazer a citação comentada, uma vez que, no lugar da comum citação transposta no espaço da epígrafe, a voz da autora - que assina no fim do trecho - emerge nesse espaço. Com tal característica, Gersão põe em questão o modo de citar no espaço da epígrafe, pois tais citações não são apenas mote para a leitura destacam-se as referências justamente da cidade "podre", em ruína, destruída e das "Memórias", palavra-chave para a construção narrativa -, como estão incluídas textualmente na obra, segundo a autora. Todo este processo de iniciar a epígrafe assume uma função fundamental em relação ao que lemos logo depois das citações comentadas: "O resto do texto também não é meu”. Assim, mais que trazer na epígrafe textos que servirão de mote para a

\footnotetext{
${ }^{1}$ Para as referências dos trechos da obra, utilizaremos $P M M F$ e o número da página.
} 
leitura, Teolinda Gersão assume a voz para apresentar um posicionamento político em Paisagem com mulher e mar ao fundo: seu texto refletirá outras vozes. A voz singular presente - por meio principalmente da voz de Hortense, protagonista do romance representará a voz do povo português. E por isso é necessário apontar para o contexto histórico que envolve o livro: essa obra foi publicada oito anos depois da Revolução dos Cravos e traz em cena a opressão e violência sofridas em tempos de guerra colonial e ditadura militar em Portugal, especialmente, no tempo referente ao comando por Oliveira Salazar referenciado, no romance em questão, pela sigla O. S.. Se lembrarmos que "na origem, o escritor é aquele que escreve no lugar dos outros. O sentido atual (autor de livros) data do século XVI" (BARTHES, 2007, p. 33), percebemos que, desse modo, Teolinda Gersão agregará ambos os significados para o termo "escritor" a fim de trazer ao espaço da representação a memória - com todas as implicações que este termo carrega - de um passado próximo que reconduziu, reconfigurou, ressignificou a história dos portugueses e que, logo após a "retomada" da liberdade, foi preciso ser compreendida. Esse contexto histórico é o pano de fundo de uma "mente" feminina, a de Hortense, ao relembrar esse tempo de repressão, que envolve o regime ditatorial, a guerra colonial e a Revolução dos Cravos em 25 de abril de 1974, nessa busca em que a memória também abrirá caminho para a tentativa de compreensão. A memória é o fio que une o passado, o presente e - por que não dizer - o futuro, já que a obra termina com um nascimento, isto é, o início de outro tempo, posterior à Revolução, como metáfora da mudança, ainda que convivendo inevitavelmente com as marcas do passado.

Diante do pano de fundo histórico carregado de violência, brutalidade e crueldade, tanto a estrutura do corpo da linguagem como a temática são revestidas de natureza metafórica em Paisagem com mulher e mar ao fundo. O corpo do texto é construído de modo desestruturado, com vírgulas que interrompem pensamentos não concluídos; parágrafos que iniciam com letras minúsculas de modo a continuar algo interrompido anteriormente que retorna "à mente" de forma desconexa; vazios breves ou longos entre os parágrafos, que são descontínuos em relação à linearidade da história. História esta que não se caracteriza pela construção de um enredo linear, mas pela estruturação feita por trechos que envolvem falas, narração e pensamentos. Os espaços vazios entre os trechos são como silêncios que, segundo Eni Orlandi, são "um lugar de recuo necessário para que se possa significar, para que o sentido faça sentido" (ORLANDI, 1992, p. 43), ou seja, que significam, neste contexto, esquecimentos ou silêncios voluntários em busca de se querer "apagar"/esquecer ou não 
registrar o terror que dilacerou a alma desse corpo que também é metafórico. Hortense é uma voz que representa as vozes desarticuladas que não puderam expressar sua dor devido à repressão do regime que se propunha a silenciar e também limitar o pensamento humano com a ideologia reproduzida incessantemente nas instituições. $\mathrm{O}$ romance vai além por agregar isso à tradição da cultura portuguesa em relação às mulheres. A própria estrutura que se observa no romance, ao imbricar fala-narração-pensamento, metaforiza a manifestação da memória do povo português, o dilaceramento da alma portuguesa, entrecortada pelo silêncio e confusa diante do seu tempo. Como diz Isabel Allegro, o estilhaçamento da escrita se dá "à maneira das próprias personagens e do próprio povo, cujas vidas aparecem de igual modo assim como que cortadas, “estilhaçadas"” (MAGALHÃES, 1987, p. 421). A caracterização de Hortense é exemplo dessa vida - e, também, dessa escrita - despedaçada:

\footnotetext{
ela era uma sombra num vidro, uma sombra passando, atravessando as coisas sem tocá-las, um corpo de vidro caindo de uma janela alta, um corpo rebentando em estilhaços de granada, para viver seria preciso recuperar-se, reunir os pedaços dispersos, primeiro a cabeça, primeiro as mãos, o rosto, primeiro os olhos, primeiro o ventre. $(P M M F$, p. 23)
}

$\mathrm{Na}$ tentativa de reunir, compreender, dar um sentido ao passado, Hortense tem o corpo como metáfora de todo um corpo social marcado pelo terror da emigração, da guerra, das prisões, do exílio, da ditadura. Corpo despedaçado este que aparece no trecho pela metonímia das partes do corpo humano: a cabeça, metáfora da mente, onde o passado deixou lembranças que se quer esquecer, mas que insistem em atormentar, porque estarão ali para sempre à espreita; as mãos, que, no romance, são os instrumentos do trabalho da mulher portuguesa, como forma de demonstrar sua submissão, mas representam também as mãos dos homens que seguram as armas levadas à guerra; o rosto, inundado de lágrimas e tristeza; os olhos que não reconhecem esse outro Portugal, esse outro mar, essa outra paisagem histórica; e o ventre, espaço "gerador" de um futuro desse país que precisa se reerguer. A revisão crítica do passado, portanto, dar-se-á pela perspectiva da subjetividade do ser humano - podemos dizer também pelas profundezas do ser humano, para usar um termo também relacionado ao mar, termo este importantíssimo, presente já no título, para a natureza metafórica do romance -, "corpo" em que mais a ditadura, a guerra e a Revolução deixaram marcas irreversíveis.

Jane Santos, na dissertação "Sob o signo do poder, escrita e subjetividade em Paisagem...", defende que pelas paisagens "particulares" de Hortense, é possível entrever as “paisagens” públicas. (SANTOS, 2006, p. 97). A natureza metafórica do romance - que, aqui, de fato, baseia-se em elementos da natureza - permite a construção desse jogo de espelhos entre a subjetividade das personagens e a "paisagem" histórica. A abertura do primeiro 
parágrafo do romance - "O que se via da janela" (PMMF, p. 9) - já inicia esse percurso metafórico da linguagem. É do interior da casa, do corpo, da memória que se olhará o que está para além do $e u$, que neste momento se encontra devastado por ter sofrido mais de quatro décadas de regime ditatorial. O título - Paisagem com mulher e mar ao fundo - já traz o tom imagético e acústico que envolverá a "paisagem" central da narrativa: a perspectiva do olhar feminino diante de um contexto histórico e o mar como símbolo principal que passa por uma ressignificação, dada a mudança dos tempos. O mar de agora é visto no inverso do mar de outrora. O mar das grandes conquistas "transforma-se" no mar de fuga, de perda, de sofrimento para os portugueses - o que permite Hortense pensar "o mar como um espelho" $(P M M F$, p. 21), da mesma maneira que mais a diante, a voz de O. S. diz: "O meu reino é um reino de espelhos, um jogo de reflexos" (PMMF, p. 95). Emerge agora o símbolo português na sua face que sempre se ocultara na alma portuguesa, já vista em vozes outras já no épico camoniano. Na primeira epígrafe deste trabalho, Fiama Hasse Pais Brandão relê o trovador do século XIII João Zorro - cuja cantiga ${ }^{2}$ vem como epígrafe desse poema -, subvertendo a imagem do mar como sinônimo de glória e o associando à guerra, de modo que as barcas agora rimam com armas que acompanham homens que partem. O jogo das palavras que se repetem de maneiras e ordens diferentes dá um caráter nauseante ao poema que reflete a dor de todo um povo que sofria com a partida, a perda, a morte nessas décadas de ditadura e guerra. O mar que sustentou o grande império português agora é o mar que posiciona Portugal como periférico (cf. LIMA, 2011). E nesse jogo espelhado entre mar e os próprios portugueses, Hortense se encontra:

Ou era no fundo do mar que estava, se saísse a porta morreria afogada entre novelos de algas e rocha escura? O ruído do mar entrara pela noite e invisivelmente diluíra as coisas, o ar e o tempo tinham deixado de existir. Ela oscilava, sem respirar, com movimentos inseguros, através da água, lutando por vencer o espaço entre os objectos - com maior força o mar começara a bater contra a janela, [...] o vento veio do meio do mar, rodopio em volta do farol e bateu contra a casa, empurrou a janela, quebrou a vidraça, a chuva entrou de roldão, um redemoinho de chuva enovelando os cortinados [...]". (PMMF, p. 10)

Agora o mar afoga, transtorna, sufoca e traz a iminência da morte no lugar de uma gloriosa busca, e a casa "portuguesa", onde se fincam as raízes e que é sinônimo de segurança, agora está fragilizada, destruída, inutilizada, como a própria Hortense se pergunta: "Para que serve a casa quanto todos partiram" (PMMF, p. 31). A identidade portuguesa

\footnotetext{
${ }^{2}$ Eis a cantiga de João Zorro que o poema de Fiama Hasse Pais Brandão traz como epígrafe: "Em Lixboa sobre lo mar / barcas novas mandei lavrar, / ay mia senhora velida! // Em Lisboa sobre lo ler / barcas novas mandei fazer, / ay mia senhora velida! // Barcas novas mandei lavrar / e no mar as mandei deitar, / ay mia senhora velida! // Barcas novas mandei fazer / e no mar as mandei meter, / ay mia senhora velida!' (Brandão, 1991)
} 
desmorona nesse contexto histórico, em que os homens estão ausentes de si próprios, “absurdamente sozinhos e vazios" (PMMF, p. 79). Não é à toa que na cena da Revolução e da queda do regime, Hortense afirma:

era a festa da morte, gritam, mas doravante é a festa da vida, ele caiu do seu trono e somos nós agora os senhores do mar e os senhores da terra, desvandámos o enigma e encontrámos a saída do seu reino, não partiremos mais porque esta terra é nossa. (PMMF, p. 114)

Destaca-se a defesa da terra como o lugar que agora voltará a significar segurança, em que sementes para outras raízes terão de ser colocadas para a nova solidificação da identidade nacional, permitindo então que os portugueses se sentissem novamente "senhores da terra", senhores de si. O poema "25 de abril", de Sophia de Mello Breyner Andresen, trazido como segunda epígrafe deste texto, associa o sentimento de liberdade após a Revolução ao ato de acordar depois de um tempo sombrio e dominante - a noite e o silêncio , além de que relaciona a liberdade à ideia de sentir o tempo, uma vez que, em tempos de opressão e guerra, era como se o tempo também estagnasse. Para além desse novo olhar sobre o mar que agora tem o peso negativo sobre os portugueses, Hortense questiona também o que o mar significou para as mulheres, que, desde o século XVI, ficavam à espera, no mundo da incerteza, à iminência da perda de seus homens:

Este ódio ao cais, às despedidas lancinantes, porque não gritar alto, assumir este cais
e estas cenas, estão em nossa vida desde há séculos, este cais de desastre, esta
amargura, é melhor assumi-lo até o fundo e gritar com os outros de puro desespero,
em vez de se iludir de falsa esperança, o que quer que aconteça é culpa minha, sou
culpada deste navio e deste cais, porque nós preferirmos culpar o destino, como se o
destino existisse, e aqui estamos há séculos de pés e mão atados, embarcando,
partindo para fora de nós mesmos, no barco da loucura, um povo sem força e sem
vontade, apenas embarcando [...]" (PMMF, p. 48).

Pelo discurso intimista, a voz de Hortense traz o discurso crítico diante da passividade e do silêncio a que as mulheres estão submetidas "há séculos" e do "destino" a que se apegam para justificar essa posição. A voz de Hortense é um grito de desespero para despertar esse povo, o que, no contexto em questão, apontaria para a ideia de Revolução. A própria Teolinda Gersão reconhece que defende uma visão crítica sobre a metáfora do mar para os portugueses: "o grande espelho narcísico que dá de nós uma imagem falsa, sobre a qual se adormece a grande voz embaladora que leva à passividade e à morte" (GERSÃO apud GOMES, 1993, p.166). A autora chama atenção justamente para a necessidade de se olhar criticamente o mar como símbolo de uma glória passada e coloca em questão essa glória vista unilateralmente, já que, desde sempre, teve o seu avesso. Ademais, não só da ausência secular 
dos homens e posição submissa da mulher lembra Hortense, mas também da ausência de si próprios, identidade esta que estava ainda mais dilacerada nesse tempo de opressão, como diz a voz feminina: "a emigração e a guerra, as duas formas de ausência". (PMMF, p. 46).

A linguagem metafórica colabora para evitar a construção do texto como mero documento histórico, para instigar a sensibilidade do leitor diante dessa experiência de crueldade e para revisar e ressignificar o passado histórico por meio da linguagem literária. Passando-se o romance à beira-mar - um mar, como vimos, de "ruínas" -, outras passagens também aproximam elementos da natureza aos tempos repressivos pelo jogo metafórico, o que já está no nome da protagonista: "o amor das plantas já vem do nome, Hortense” ( $P M M F$, p. 64). Assim, tanto a natureza do romance é metafórica como se utiliza, pelo jogo com a linguagem, de elementos da natureza - esta literal - para a construção do romance. Ao se referir às imposições de O. S., Hortense "lembra": "a sua mão parava o vento da mudança e espalhava a areia negra do medo" (PMMF, p. 66). A metonímia da mão para os tentáculos de um governo que "estava" em todo lugar, seja pelos seus funcionários ou também por seus professores - como se vê no romance - relaciona-se com o metafórico vento que estagna o tempo e traz a "areia", isto é, aquilo que embaça a visão e dificulta o avanço - no sentido de ir e vir - dos homens, obrigando-lhes a paralisar.

Se a casa não podia ser mais o refúgio que se podia ter, era interiormente, nos afetos, que então que as pessoas buscavam fincar-se. Ainda que a casa de Hortense conseguisse ser, em alguns momentos, espaço para liberdade de pensamento e era onde reinava o amor e certa esperança, ela estava susceptível a toda a força opressora que lhe cercava. Portanto, era somente no amor por Horário que Hortense conseguia sentir-se completamente segura - "ele era uma casa de que ela possuía a chave, assim ele se entregava e ficava sem defesa, vulnerável" (PMMF, p. 70) - e sentir-se dona de si e, de certo modo, liberta:

Sentada sozinha no mesmo local da sala, um espaço para existir, para assumir-se tal como era, sem jamais sofrer sanção alguma. Fora isso que ela sempre desejara, obscuramente, sem ter consciência clara do que procurava: a liberdade de viver sem culpa e sem revolta. Ele dera-lhe a possibilidade de ir até ao fim de si mesma". $(P M M F$, p. 71)

E como se trata de um romance sobre o povo português, também o homem, em momento opressor, precisou buscar uma segurança no interior humano - "Ela [Hortense] seria o seu único ponto de fuga" (PMMF, p. 76) - e acreditar em uma momentânea tranquilidade: "haveria sempre a casa-corpo" (PMMF, p. 77). Denilson Lopes, diante da problemática questão “o que fazer quando se está diante de uma realidade cruel?”, baseia-se nas palavras de Schollhammer e Levy para responder: 
Ao invés da estética do efeito, implícita nas técnicas expositivas do choque, do grotesco e do escândalo; o desafio artístico se colocaria em termos de uma estética do afeto, entendida aqui como o surgimento do estímulo imaginativo que liga a ética diretamente à estética; não mais uma arte de limites, de transgressão, mas de possibilidades”. (SCHOLLHAMMER \& LEVY apud Lopes, 2007, p. 90)

$\mathrm{Na}$ arte e no afeto estão os espaços de fuga, de solidariedade e de incitação à liberdade nos quais a voz de Hortense insiste em todo o romance. A esperança estava nessa relação que momentaneamente afagava os corações e motivava a busca pela liberdade, e que também fundamentaria a ideia de Revolução, também presente no romance: "a força que havia no amor, numa relação de solidariedade e não de supremacia nem domínio, as pessoas reciprocamente apoiando-se, trabalhando juntas para um mesmo fim. Um outro universo, um outro imaginário" (PMMF, p. 72). No caminho da resposta para o desafio proposto por Renato Cordeiro Gomes - "Como transmitir a experiência do horror e não só informar sobre ele?" (GOMES, 2004, p. 150) -, Paisagem... traria, por meio do lirismo e do jogo metafórico da linguagem, a afetividade e a solidariedade entre os indivíduos. Sobre esse "pingo" - para nos espelharmos na metáfora do mar presente no livro - de esperança que Hortense consegue vislumbrar por um posicionamento crítico e pelo amor vivido, que a impede de cometer suicídio e a faz acreditar na vida após o nascimento do neto, Ângela Beatriz Faria assevera: "Ao elidir o luto e libertar as personagens da queda irreversível no abismo da melancolia, o romance reafirma a ultrapassagem dos sentidos e a presença de corpos ativos e solidários na História" (FARIA, 2005, p. 8).

Ademais, a pintura tanto é estratégia para a construção do texto de Gersão, uma vez que todo o romance é carregado pelo tom imagético a fim de trazer tanto o choque da mudança da "paisagem" histórica sofrida por Portugal em tempos de ditadura, guerra e Revolução, quanto é o outro espaço de fuga dos protagonistas. A arte pictórica surge como espaço em que é possível alimentar a capacidade de imaginação humana em forma de resistência ao ensino direcionado pelo salazarismo nas escolas e também como metáfora de criar e reposicionar a "paisagem" que se encontra "emoldurada" e "fixa" durantes décadas em Portugal. Essa metáfora é feita no próprio corpo do texto pela voz da protagonista:

\footnotetext{
a loucura de pendurar um quadro na parede e de encontrar para ele um álibi ingénuo e manso: rasgar uma brecha por onde um outro universo entrasse, abrir um pássaro, uma luz, uma janela na parede dos dias, e as pessoas não ficariam mais emparedadas enquanto olhassem, um modo de libertar o olhar (PMMF, p. 74)
}

Nas pinturas de Hortense e Horácio, "seria sempre possível mudar o sol, e colocá-lo do outro lado, no desenho." (PMMF p. 33). Pela voz de Hortense, o sol, mais um elemento natural significativo no romance, é o seu símbolo de busca pela liberdade e mudança, em que 
a "iluminação" não permite a paralisação e instiga, portanto, o pensamento da revolta. Contra tudo isso, estava o ensino escolar, que, sob tais contextos, trazia como lema a ideia de que "educar era reprimir desde a infância" (PMMF, p. 89). Na cena em que a professora, um dos tentáculos de O. S., repreende Hortense criança por não ter repetido o que pregava o ensino "Uma árvore é uma árvore, porque é que desenhou uma árvore como se fosse um pássaro?" $(P M M F$, p. 80) -, a protagonista já demonstrava seu posicionamento contra o regime opressivo. Por meio do desenho, a imagem engessada e acrítica repassada para as crianças é desconstruída e combatida por Hortense. As imagens da árvore e do pássaro elucidam claramente a contraposição entre a imobilidade de pensamento imposta pelo regime e o movimento do pensamento de Hortense, que permitia e desejava alçar voos mais altos em direção à liberdade. Pela brutal realidade trazida pelo jogo metafórico da linguagem, observase que Paisagem... apresenta o caminho que Renato Cordeiro Gomes aponta para se conseguir transmitir a crueldade: "Talvez só olhando de viés, das margens da própria realidade brutal, se passa ver sua crueldade, sem necessariamente, ser preciso um pouco de sangue para manifestá-la" (GOMES, 2004, p. 154). A estrutura metafórica, o lirismo e a subjetividade das personagens são estrategicamente construídos por Teolinda Gersão para alcançar o leitor em sua subjetividade. Desse modo, Paisagem com mulher e mar ao fundo se encerra no "desejo de quebrar toda tentativa de permanência de autoritarismo, seja na linguagem, seja na interioridade dos sujeitos" (COSTA, 2011, p. 9). É, então, no espaço da linguagem literária que a liberdade tem espaço privilegiado, pois é esse o único espaço em que vozes como a de Hortense puderam alcançar eco e espaço.

Pela memória de Hortense e as outras vozes do romance, depara-se com a devastação que os anos de Estado Novo deixaram na alma - no sentido da memória cultural, consciência do ser humano - portuguesa: um estilhaçamento do seu orgulho, muitas vezes bem defendido pelo patriotismo, de sua capacidade de desbravamento do mundo, que não só retira a voz do povo, mas sua capacidade de dar sentido à vida. Gersão utiliza-se de um dos símbolos nacionais mais importantes para construir, por meio dessa paisagem, a imagem das mudanças trazidas pelo período histórico profundamente marcante para Portugal. A paisagem do mar e seus elementos circundantes, metaforicamente, serviram como espelho de um povo que se encontra em confronto em busca de ressignificar os elementos significativos de seu imaginário após um esmagamento e estilhaçamento do pensamento e das relações sociais e políticas causados pela ditadura, guerra e Revolução. Se aqui se retrata a luta pela voz - de O.S. e do povo -, o que vence é a voz do romance por meio do trabalho da linguagem, o que 
está de acordo com o que afirma Eduardo Lourenço sobre a relação entre a literatura e o "25 de abril": "a Revolução inventou-nos não só no presente como no passado, uma outra memória de nós mesmos [...] e desse poder autónomo do texto ficcional e verbal, nós saímos [...] do conúbio Revolução-reflexo escrito para entrarmos em cheio na revolução da escrita" (LOURENÇO, 1984, p. 16). Pela perspectiva do olhar e recriação do mundo, metaforizado pelo símbolo do mar e seus elementos naturais correlacionados, constrói-se, no espaço da linguagem, uma tentativa de um novo olhar - e também de uma revisão do olhar - sobre a identidade e a história portuguesas.

\section{Referências}

ANDRESEN, Sophia de Mello Breyner. Obra poética. Alfragide: Editorial Caminho, 2011.

BARTHES, Roland. Crítica e verdade. Trad. Leyla Perrone-Moisés. São Paulo: Perspectiva, 2007. (Debates; 24 / dirigida por J. Guinsburg)

BRANDÃO, Fiama Hasse Pais. Obra Breve. Lisboa: Editorial Teorema, 1991.

COSTA, Daniela. Paisagem com mulher e mar ao fundo: a paisagem e outras paisagens. In: Anais do XXIII Congresso Internacional da Associação Brasileira de Professores de Literatura Portuguesa. São Luís, 2011. p. 1529-1538.

FARIA, Ângela Beatriz. Na ultrapassagem dos sentidos, a presença de corpos ativos e solidários na História. In: XX Encontro de Professores Brasileiros de Literatura Portuguesa: no limite dos sentidos. Instituto de Letras da UFF, 2005. CD-ROM.

GERSÃO, Teolinda. Paisagem com mulher e mar ao fundo. 3. ed. Lisboa: Edições O Jornal, 1985.

GOMES, Álvaro Cardoso. A Voz Itinerante: ensaio sobre o Romance Português Contemporâneo. São Paulo: Edusp, 1993.

GOMES, Renato Cordeiro. Narrativa e paroxismo: será preciso de sangue verdadeiro para manifestar a crueldade?. In: Estéticas da crueldade. Rio de Janeiro: Atlântica Editora, 2004. p. 143-154.

LIMA, Isabel Pires de. Portugal, cais de chegada. In: Rios, Otávio. (Org.). Arquipélagos contínuos: literaturas plurais. Manaus: UEA Edições, 2011. p. 65-79.

LOPES, Denilson. Poética do cotidiano. In: A delicadeza: estética, experiência e paisagens. Brasília: Editora UNB, Finatec, 2007. p. 83-97.

LOURENÇO, Eduardo. Dez anos de literatura portuguesa (1974-1984): Literatura e Revolução. In: Colóquio/Letras. Balanço, n. 78, Mar. 1984, p. 7-16.

MAGALHÃES, Isabel Allegro de. O tempo de Paisagem com mulher e Mar ao fundo. In: $O$ tempo das mulheres: a dimensão temporal na escrita feminina contemporânea (ficção portuguesa). Lisboa: Imprensa Nacional - Casa da Moeda, 1987. P. 420-460. 
ORLANDI, Eni Puccinelli. As formas do silêncio: no movimento dos sentidos. São Paulo: editora da Unicamp, 1992.

SANTOS, Jane Rodrigues. Sob o signo do poder, escrita e subjetividade, em Paisagem com mulher e mar ao fundo, de Teolinda Gersão. 2006. 111 f. Dissertação (Mestrado em Estudos de Literatura) - Faculdade de Letras, Universidade Federal Fluminense, Niterói. 2006.

[Recebido em junho de 2013 e aceito para publicação em outubro de 2013]

Another sea, another self: a reading about the metaphorical nature of Paisagem com mulher e mar ao fundo

Abstract: The work Paisagem com mulher e mar ao fundo, by Teolinda Gersão, was published eight years after the Carnation Revolution and brought as the background decades of dictatorship in Portugal. Given this context, the moment when it was necessary to resignify and review the recent past in order to understand it, we intend to analyze in which ways the language can be the place where a new view emerges over the past of cruelty and suffering. In this work, we will see how the metaphor and metonymy can promote the resignification of the language. Like the landscape, the view over the sea - symbol of the portuguese culture, memory and history -, next to their surrounding elements, will be revisited and reviewed, under that context. The characters' "shattered" bodies will be the metaphor of a destroyed portuguese social body and wrecked cultural identity. The studies of Roland Barthes, Renato Cordeiro Gomes, Ângela Beatriz Faria, Denilson Lopes, Eduardo Lourenço, among others, will be the groundings for this work.

Keywords: Paisagem com mulher e mar ao fundo. Teolinda Gersão. Memories. Salazarism. Carnation Revolution.

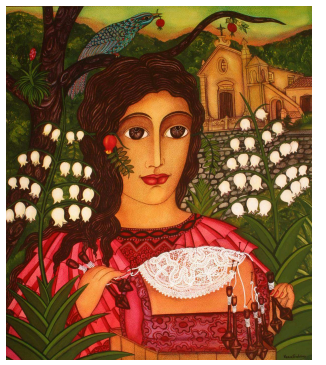

